\title{
A selenium species in cerebrospinal fluid predicts conversion to Alzheimer's dementia in persons with mild cognitive impairment
}

\author{
Marco Vinceti ${ }^{1,2,3^{*}}$, Annalisa Chiari ${ }^{2,4}$, Marcel Eichmüller ${ }^{5}$, Kenneth J. Rothman ${ }^{3,6}$, Tommaso Filippini $^{1}$, \\ Carlotta Malagoli', Jennifer Weuve ${ }^{3}$, Manuela Tondelli ${ }^{2,4}$, Giovanna Zamboni ${ }^{2}$, Paolo F. Nichellii, \\ and Bernhard Michalke ${ }^{5}$
}

\begin{abstract}
Background: Little is known about factors influencing progression from mild cognitive impairment to Alzheimer's dementia. A potential role of environmental chemicals and specifically of selenium, a trace element of nutritional and toxicological relevance, has been suggested. Epidemiologic studies of selenium are lacking, however, with the exception of a recent randomized trial based on an organic selenium form.

Methods: We determined concentrations of selenium species in cerebrospinal fluid sampled at diagnosis in 56 participants with mild cognitive impairment of nonvascular origin. We then investigated the relation of these concentrations to subsequent conversion from mild cognitive impairment to Alzheimer's dementia.

Results: Twenty-one out of the 56 subjects developed Alzheimer's dementia during a median follow-up of 42 months; four subjects developed frontotemporal dementia and two patients Lewy body dementia. In a Cox proportional hazards model adjusting for age, sex, duration of sample storage, and education, an inorganic selenium form, selenate, showed a strong association with Alzheimer's dementia risk, with an adjusted hazard ratio of 3.1 (95\% confidence interval 1.0-9.5) in subjects having a cerebrospinal fluid content above the median level, compared with those with lower concentration. The hazard ratio of Alzheimer's dementia showed little departure from unity for all other inorganic and organic selenium species. These associations were similar in analyses that measured exposure on a continuous scale, and also after excluding individuals who converted to Alzheimer's dementia at the beginning of the follow-up.
\end{abstract}

Conclusions: These results indicate that higher amounts of a potentially toxic inorganic selenium form in cerebrospinal fluid may predict conversion from mild cognitive impairment to Alzheimer's dementia.

Keywords: Mild cognitive impairment, Alzheimer's disease, Dementia, Selenium, Selenium species, Cerebrospinal fluid

\footnotetext{
*Correspondence: marco.vinceti@unimore.it

'CREAGEN-Environmental, Genetic, and Nutritional Epidemiology Research Center, Department of Biomedical, Metabolic, and Neural Sciences, University of Modena and Reggio Emilia, 287 Via Campi, Modena 41125, Italy

${ }^{2}$ Center for Neurosciences and Neurotechnology, Department of Biomedical, Metabolic, and Neural Sciences, University of Modena and Reggio Emilia, 287 Via Campi, Modena 41125, Italy

Full list of author information is available at the end of the article
}

(c) The Author(s). 2017 Open Access This article is distributed under the terms of the Creative Commons Attribution 4.0 International License (http://creativecommons.org/licenses/by/4.0/), which permits unrestricted use, distribution, and reproduction in any medium, provided you give appropriate credit to the original author(s) and the source, provide a link to the Creative Commons license, and indicate if changes were made. The Creative Commons Public Domain Dedication waiver (http://creativecommons.org/publicdomain/zero/1.0/) applies to the data made available in this article, unless otherwise stated. 


\section{Background}

Neurodegenerative dementias are well-recognized, severe medical conditions that are prevalent worldwide and expected to rise in western countries in the coming years [1, 2]. Effective therapies are lacking, as is adequate knowledge of their risk factors. In addition to genetic susceptibility, there is increasing evidence that environmental determinants, including environmental pollutants [3, 4], are important in dementia etiology. Among the large number of chemical factors that have been implicated in the etiology of dementia, particularly its most common form, Alzheimer's dementia (AD), recent concern has focused on both increased and decreased exposure to the metalloid selenium (Se), an element of strong nutritional and toxicological interest [5-8]. Se exists in several chemical species with markedly different and even opposite biological properties [9-11]. In its selenocysteine-bound organic form, Se is an indispensable component in selenoprotein biosynthesis [7, 12], while other organic species such as selenomethioninebound Se $[13,14]$ and the inorganic forms such as selenate or selenite [11, 15-17] are also well recognized as powerful toxicants. Se exposure in the human mainly occurs through diet and in its organic forms, its major sources being meat and fish, cereals, eggs, and dairy products $[18,19]$. Se has been a topic of interest in recent decades mainly with reference to its possible role in cancer prevention and therapy [20-22]. More recently, its involvement in human brain pathology, and particularly with the risk of amyotrophic lateral sclerosis and $\mathrm{AD}$, has become a focus $[17,23-29]$. Such a relation, however, may exist only for some Se species, and particularly for the inorganic ones [30, 31].

However, while the results of a randomized trial assessing the effect of selenomethionine supplementation in dementia prevention have been published recently [32], there are no observational cohort studies specifically taking into account the speciation of the different chemical forms of Se in relation to the risk of AD.

We collected cerebrospinal fluid (CSF) samples in a cohort of Italian participants diagnosed with mild cognitive impairment (MCI) [33]. These participants were then followed for occurrence of dementia, enabling us to assess the relation between concentrations of various Se species in CSF and the risk of conversion to AD or other dementia.

\section{Methods}

Study cohort

As shown in the flowchart (Fig. 1), following approval by the Modena Ethics Committee, we considered as eligible for our cohort study all participants who received a clinical diagnosis of MCI (amnestic MCI, single domain or multiple domain, or nonamnestic MCI [34, 35]) and who were admitted from 2008 to 2014 to the Neurology Memory Clinic of Sant'Agostino-Estense Hospital of Modena, Italy. Participants were then further selected if, following informed consent, they underwent a lumbar puncture (LP) for diagnostic purposes and had no brain imaging abnormalities or medical history suggestive of a vascular origin of their cognitive impairment [33, 36, 37]. Out of 71 potentially eligible

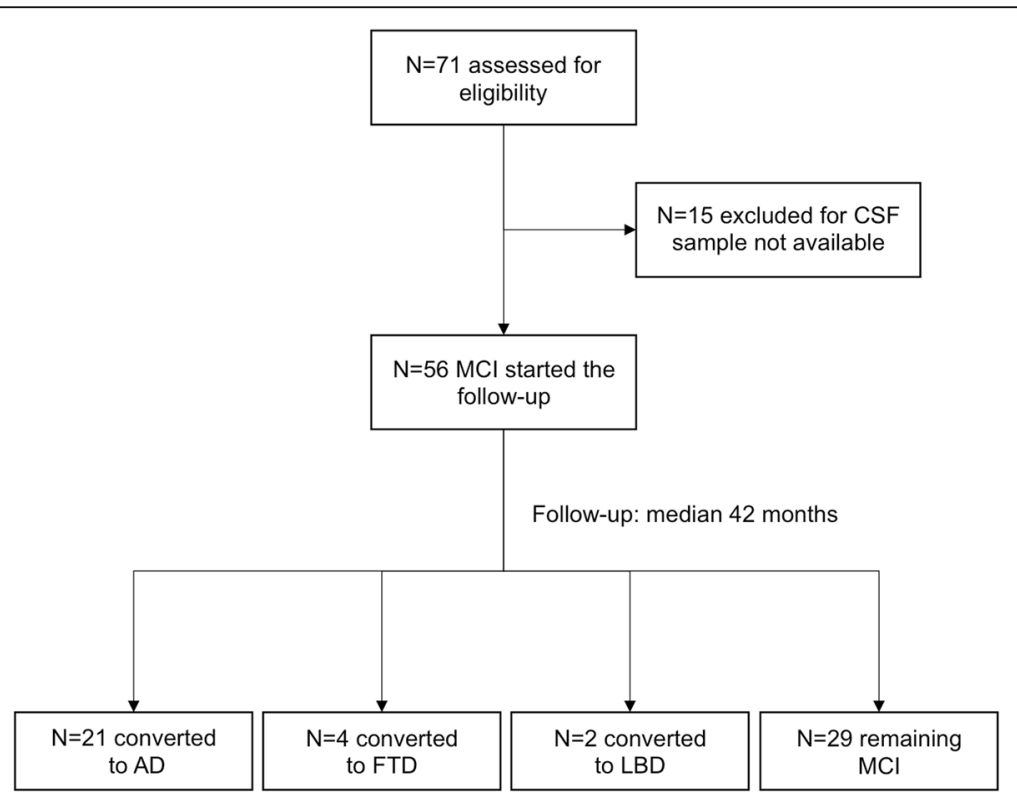

Fig. 1 Flowchart for design of the cohort study. AD Alzheimer's dementia, CSF cerebrospinal fluid, FTD frontotemporal dementia, LBD Lewy body dementia, MCl mild cognitive impairment 
participants, 56 had $1 \mathrm{~mL}$ of CSF or more available, and these constituted the cohort for the present study.

At baseline, all participants underwent routine blood tests, neurological and neuropsychological examination, and brain MRI. They also had a LP (within 1 month of clinical and neuropsychological examination) to measure CSF levels of $A \beta_{1-42}(\beta$-amyloid), total tau ( $t$-tau), and phosphorylated tau (p-tau) proteins. APOE $\varepsilon 4$ allele status was determined for 39 participants. All participants were subsequently followed up every 6 months through December 2016. At each visit they were classified according to whether their condition was stable or had converted to any clinical type of dementia, including $\mathrm{AD}$ [38], Lewy body dementia (LBD) [39], and frontotemporal dementia (FTD) $[40,41]$.

\section{Analytical determinations}

Lumbar punctures were performed using a standard procedure to minimize the risk of biological and chemical contamination [17]. We collected CSF in sterile polypropylene tubes, which were transported to the adjacent laboratory within 30 min of collection. We centrifuged CSF for $15 \mathrm{~min}$ at $2700 \times g$ at controlled room temperature and aliquoted into polypropylene storage tubes. CSF $\beta$-amyloid, t-tau, and p-tau 181 were measured as described previously [33]. The remaining, anonymized aliquots were immediately stored at $-80{ }^{\circ} \mathrm{C}$ and later transported deep frozen in dry ice by air courier to the element speciation laboratory at the Helmholtz Zentrum München, and kept continuously frozen until use.

We determined total Se by inductively coupled plasma dynamic reaction cell mass spectrometry (ICP-DRC-MS) and the Se species-selenite (Se(IV)), selenate (Se(VI)), selenomethionine-bound Se (Se-Met), selenocysteinebound $\mathrm{Se}$ (Se-Cys), thioredoxin reductase-bound $\mathrm{Se}$ (Se-TXNRD), glutathione-peroxidase-bound Se (Se-GPX), selenoprotein P-bound Se (Se-SelenoP), and human serum albumin-bound Se (Se-HSA)-in CSF samples using ion exchange chromatography (IEC) coupled with ICP-DRCMS, using methodologies we developed specifically for CSF [42, 43]. For total Se determination, CSF samples were diluted $1 / 10$ with Milli-Q water $+R h$ as internal standard $(1 \mu \mathrm{g} / \mathrm{L}$ final $\mathrm{Rh}$ concentration). For Se speciation, a Knauer 1100 Smartline inert Series gradient HPLC system was connected to an ion exchange column AS-11 (250 mm $\times 4 \mathrm{~mm}$ ID) from Thermo Fischer Scientific Inc. (Sunnyvale, CA, USA) for species separation. The sample volume (undiluted CSF) was $20 \mu$ l. Samples were determined in duplicate. The mobile phase consisted of eluent A (3.33 mM Tris-HAc buffer, 5\% methanol, $\mathrm{pH} 8.0)$ and eluent B (10 mM Tris-HAc buffer, $500 \mathrm{mM}$ ammonium acetate, $5 \%$ methanol, $\mathrm{pH} 8.0$ ). Gradient elution was as follows: $0-3$ min $100 \%$ eluent A (0\% eluent B); 3-10 min
$100-60 \%$ eluent $A ; 10-23$ min $60-45 \%$ eluent $A ; 23-$ 26 min $45-43 \%$ eluent A; $26-28$ min $43-0 \%$ eluent A; 28-52 min 0\% eluent A; 52-60 min 100\% eluent A. The flow rate was constant at $0.8 \mathrm{~mL} / \mathrm{min}$. The column effluent was directed to ICP-DRC-MS. The experimental settings for ICP-DRC-MS (NexIon 300 D; Perkin Elmer) were: radiofrequency power $1250 \mathrm{~W}$; plasma gas flow $15 \mathrm{~L}$ $\mathrm{Ar} / \mathrm{min}$; auxiliary gas flow $1.05 \mathrm{~L} \mathrm{Ar} / \mathrm{min}$; nebulizer gas flow $0.92 \mathrm{~L} \mathrm{Ar} / \mathrm{min}$; daily optimized dwell time $300 \mathrm{~ms}$; ions monitored ${ }^{77} \mathrm{Se},{ }^{78} \mathrm{Se},{ }^{80} \mathrm{Se}$, and ${ }^{103} \mathrm{Rh}\left({ }^{103} \mathrm{Rh}\right.$ was used as internal standard for total Se determination); DRC reaction gas $\mathrm{CH}_{4}$ reaction at $0.58 \mathrm{~mL} / \mathrm{min}$; and DRC rejection parameter $q 0.6$. Five-point calibration curves with calibration points at 100, 500, 1000, 2000, and $5000 \mathrm{ng} \mathrm{Se/L}$ were linear with $r^{2}$ for the three Se isotopes being better than 0.999881. Data files from Se chromatograms were processed with Peakfit ${ }^{\mathrm{mw}}$ software for peak area integration.

Concerning the analytical figures of merit and analytical quality control, the limit of detection (LOD) was $19.5 \mathrm{ng} \mathrm{Se} / \mathrm{L}$ for Se species. Only values above the LOD are reported throughout the manuscript. Accuracy of Se determination and Se species quantification was checked by analyzing control materials and a certified reference material: quality control for total Se determination was performed by analyzing control materials 'human serum' and 'urine' from Recipe (Munich, Germany). Control materials were reconstituted as indicated on the flask labels. The resulting solutions were diluted 1/50 (serum, measurement concentration $1.25 \mu \mathrm{g} / \mathrm{L}$ ) or $1 / 10$ (urine, measurement concentration $2.35 \mu \mathrm{g} / \mathrm{L}$ ) with Milli-Q water before measurements for adjusting the measurement concentration to the expected concentration range of CSF (no CSF reference material for Se was available). Accuracy values were $98.4 \pm 3.8 \%$ (serum) and $102.1 \pm$ $5.4 \%$ (urine).

The certified reference material NIST 1950 (National Institute of Standards and Technology, Gaithersburgh, MD, USA) was used for quality control regarding total $\mathrm{Se}$, Se-SelenoP, Se-GPX, and Se-HSA. Accuracy values were $103 \pm 5.1 \%$ (Se-SelenoP, target value $=100 \%$ : $50.2 \pm$ $4.3 \mu \mathrm{g} / \mathrm{kg}$ ), $93 \pm 3.1 \%$ (Se-GPX, target value $=100 \%: 23.6$ $\pm 1.3 \mu \mathrm{g} / \mathrm{kg}$ ), and $97 \pm 1.7 \%$ (Se-HSA, target value $=$ $100 \%: 28.2 \pm 2.6 \mu \mathrm{g} / \mathrm{kg}$ ).

\section{Data analysis}

For analytical values below the LOD, we input half of the threshold [44, 45]. Most participants had Se species well above the LOD (from 89 to $100 \%$ depending on the single Se form), with lower values only for the three organic Se species Se-Cys, Se-GPX, and Se-TXNRD, which had values above the LOD only in $21 \%, 43 \%$, and $0 \%$ of the participants, respectively. We assessed the association between Se species through Spearman correlation. To evaluate the possible influence of Se species on $\beta$ - 
amyloid and p-tau, we also fitted a linear regression model of log-transformed CSF concentrations of $\beta$ amyloid and, separately, p-tau at baseline. In both the Spearman correlation analysis and the linear regression analysis, values of Se species below the LOD were excluded. After defining the person-time of follow-up as the time of $\mathrm{MCI}$ diagnosis/CSF sampling until the last follow-up visit, December 2016, or the date of $\mathrm{AD} / \mathrm{de}$ mentia diagnosis, whichever occurred first, we estimated the hazard ratio (HR) of progressing to $\mathrm{AD}$ (as well as to any dementia subtype, i.e., AD + FTD + LBD) in a Cox proportional hazards model. After assessing all variables for the proportional hazard assumption, we fitted a multivariable Cox model stratified by sex, and adjusted for age (years), education (years), and duration of sample storage (years).

\section{Results}

Table 1 reports the main demographic and clinical characteristics of MCI cohort members at baseline according to dementia diagnosis during the follow-up, and Table 2 reports their CSF concentrations of Se species, $\beta$ amyloid, $\mathrm{t}$-tau, and p-tau. Of the original 56 participants, 21 converted to AD, four to FTD, and two to LBD, and 29 did not convert at the end of the follow-up. Followup lasted on average 43.3 months, with a median of 42 months and an interquartile range of 30.4-51.2, with a total number of person-months of follow-up equal to 2423.5 .
When we assessed the correlation between Se species, the only forms not associated with total Se were $\mathrm{Se}(\mathrm{VI})$, Se-GPX, and Se-Cys, the latter form being also unrelated to total organic Se. Inorganic Se (particularly $\mathrm{Se}(\mathrm{VI})$ ) was inversely correlated with organic Se and particularly Se-SelenoP and Se-Met. Se-HSA was directly correlated with all Se species and categories except for Se-Met, Se-Cys, and Se-GPX. However, all correlations involving Se-Cys and especially Se-GPX were based on a small number of individuals, because a large proportion of the sample concentrations fell below the LOD.

Inorganic $\mathrm{Se}$ and $\mathrm{Se}(\mathrm{VI})$ concentrations in baseline CSF samples were inversely associated with CSF $\beta$ amyloid concentration (Table 3). By contrast, higher organic Se concentration and particularly Se-Met in CSF were associated with higher CSF $\beta$-amyloid. There was little evidence of an association of any Se species in CSF with CSF concentration of p-tau; $\mathrm{Se}(\mathrm{VI})$ showed some evidence of a direct relation with this protein, although this was statistically unstable as shown by the wide confidence interval of the regression coefficient. Further adjustment for APOE $\varepsilon 4$ allele carriership did not substantially change the results (Additional file 1: Table S1).

Results of the proportional hazards regression analysis are reported in Table 4. We observed an excess, albeit statistically unstable, AD risk associated with higher total $\mathrm{Se}$, with exposure classified into a dichotomy, above or below the median both in the crude analysis and taking

Table 1 Baseline characteristics of study population according to diagnosis at the end of follow-up

\begin{tabular}{|c|c|c|c|c|c|c|c|c|}
\hline & \multicolumn{2}{|l|}{$\mathrm{MCl}$} & \multicolumn{2}{|l|}{$A D$} & \multicolumn{2}{|l|}{ FTD } & \multicolumn{2}{|l|}{$\underline{L B D}$} \\
\hline & $\bar{N}$ & (\%) & $\bar{N}$ & (\%) & $\bar{N}$ & (\%) & $\bar{N}$ & (\%) \\
\hline All participants & 29 & $(100)$ & 21 & (100) & 4 & $(100)$ & 2 & $(100)$ \\
\hline \multicolumn{9}{|l|}{ Sex } \\
\hline Males & 17 & $(58.6)$ & 10 & $(47.6)$ & 2 & $(50.0)$ & 1 & (50.0) \\
\hline Females & 12 & $(41.4)$ & 11 & $(52.4)$ & 2 & $(50.0)$ & 1 & $(50.0)$ \\
\hline \multicolumn{9}{|l|}{ Age at entry } \\
\hline$<65$ years & 14 & $(48.3)$ & 6 & $(28.6)$ & 4 & $(100)$ & - & \\
\hline$\geq 65$ years & 15 & $(51.7)$ & 15 & $(71.4)$ & - & & 2 & $(100)$ \\
\hline \multicolumn{9}{|l|}{ Education } \\
\hline$<8$ years & 11 & $(37.9)$ & 5 & $(28.8)$ & - & & 2 & $(100)$ \\
\hline $8-12$ years & 8 & $(27.6)$ & 8 & $(38.1)$ & 4 & $(100)$ & - & \\
\hline$\geq 13$ years & 10 & $(34.5)$ & 8 & $(38.1)$ & - & & - & \\
\hline \multicolumn{9}{|l|}{ APOE $\varepsilon 4$ carriership } \\
\hline Noncarriers & 14 & $(48.3)$ & 4 & $(19.0)$ & 2 & $(50.0)$ & 1 & $(50.0)$ \\
\hline Carriers & 8 & $(27.6)$ & 9 & $(42.9)$ & - & & 1 & $(50.0)$ \\
\hline Missing & 7 & $(24.1)$ & 8 & $(38.1)$ & 2 & $(50.0)$ & - & \\
\hline Months of follow-up a & 44.4 & $(31.1-55.3)$ & 35.5 & $(29.6-47.4)$ & 43.1 & - & 38.5 & - \\
\hline
\end{tabular}

$A D$ Alzheimer's dementia, $A P O E$ apolipoprotein $\mathrm{E}, F T D$ frontotemporal dementia, $L B D$ Lewy body dementia, $M C I$ mild cognitive impairment ${ }^{a}$ Median (interquartile range) 
Table 2 Distribution of levels of selenium species and $\beta$-amyloid, t-tau, and p-tau at baseline in cerebrospinal fluid of the study population according to diagnosis at the end of follow-up

\begin{tabular}{|c|c|c|c|c|c|c|}
\hline & \multicolumn{2}{|l|}{$\mathrm{MCl}(N=29)$} & \multicolumn{2}{|l|}{$A D(N=21)$} & \multirow{2}{*}{$\begin{array}{l}\text { FTD }(N=4) \\
50 \text { th percentile }\end{array}$} & \multirow{2}{*}{$\begin{array}{l}\mathrm{LBD}(N=2) \\
50 \text { th percentile }\end{array}$} \\
\hline & 50th percentile & IQR & 50th percentile & IQR & & \\
\hline Total Se (nmol/L) & 51.67 & $(47.11-57.75)$ & 55.72 & $(45.97-64.46)$ & 47.87 & 59.27 \\
\hline Inorganic Se (nmol/L) & 7.98 & $(5.83-9.50)$ & 8.49 & $(5.45-10.13)$ & 7.47 & 9.50 \\
\hline Se(IV) & 5.19 & $(4.31-7.22)$ & 5.07 & $(3.80-7.85)$ & 6.46 & 8.49 \\
\hline $\mathrm{Se}(\mathrm{VI})$ & 1.52 & $(1.14-3.93)$ & 2.91 & $(1.65-4.31)$ & 1.01 & 1.01 \\
\hline Organic Se (nmol/L) & 23.81 & $(16.21-28.75)$ & 20.26 & $(13.04-27.61)$ & 18.24 & 29.89 \\
\hline Se-SelenoP & 20.64 & $(15.20-25.84)$ & 18.36 & $(11.90-23.18)$ & 16.34 & 26.72 \\
\hline Se-Met & 1.65 & $(1.01-2.79)$ & 1.90 & $(0.89-2.91)$ & 1.39 & 3.17 \\
\hline Se-Cys & 0.13 & $(0.13-0.13)$ & 0.13 & $(0.13-0.13)$ & 0.13 & 0.13 \\
\hline Se-GPX & 0.13 & $(0.13-1.14)$ & 0.13 & $(0.13-0.76)$ & 0.51 & 0.13 \\
\hline Se-HSA (nmol/L) & 17.73 & $(14.69-22.67)$ & 20.90 & $(14.69-23.30)$ & 17.22 & 16.08 \\
\hline Unknown (nmol/L) & 3.17 & $(1.77-4.56)$ & 3.55 & $(2.03-5.95)$ & 1.90 & 4.18 \\
\hline$\beta$-amyloid (pg/mL) & 699 & $(521-963)$ & 506 & $(417-519)$ & 761 & 611 \\
\hline t-tau (pg/mL) & 256 & $(198-404)$ & 625 & $(404-743)$ & 222 & 355 \\
\hline p-tau (pg/mL) & 60 & $(46-85)$ & 86 & $(73-128)$ & 47 & 67 \\
\hline
\end{tabular}

$A D$ Alzheimer's dementia, $\beta$-amyloid $A \beta_{1-42}$, FTD frontotemporal dementia, IQR interquartile range, $L B D$ Lewy body dementia, $M C I$ mild cognitive impairment, $p$-tau phosphorylated tau protein, Se selenium, Se(IV) selenite, Se(VI) selenate, Se-SelenoP selenoprotein P-bound Se, Se-Met selenomethionine-bound Se, Se-Cys selenocysteine-bound Se, Se-GPX glutathione-peroxidase-bound Se, Se-HSA human serum albumin selenium-bound Se, $t$-tau total tau protein

into account age and sex, time elapsed since year of first storage, and education. When looking at the single Se species, we found a strongly increased AD risk associated with $\mathrm{Se}(\mathrm{VI})$ exposure and to a lesser extent with Se-Met, and more weakly with Se-HSA. Results were roughly comparable in the analysis based on continuous values of Se exposure (both one-unit and one-standarddeviation increase; data not shown). When we adjusted for $\beta$-amyloid and $\mathrm{p}$-tau, in addition to age and sex, we obtained HRs comparable with those obtained in the less adjusted analysis, although in this adjusted model the excess risk associated with overall Se, organic Se, Se-SelenoP, and particularly Se-Met levels was enhanced, and that associated with $\mathrm{Se}(\mathrm{VI})$ was reduced. Finally, adding APOE $\varepsilon 4$ status to the most adjusted multivariable model shown in Table 4 had little effect on the estimates (Additional file 1: Table S2), with the exception of the HR associated with selenate which became 7.6 (95\% CI 1.2-49.5). However, results of the latter analysis were statistically less stable due to fewer participants (for a few cohort members this genetic datum was not available) and more variables in the model.

When we replaced AD with any dementia occurrence in the aforementioned analyses, effect estimates were substantially unchanged (data not shown). We also repeated the aforementioned Cox analysis by omitting the AD cases detected after the first 2 years of follow-up (two participants): results were substantially unchanged, with the HR associated with selenate levels above the median being 3.5 (95\% CI 1.0-11.9).
When we stratified the analysis according to the APOE $\varepsilon 4$ status, a direct association of $\mathrm{Se}(\mathrm{VI})$ with $\mathrm{AD}$ risk emerged in both APOE $\varepsilon 4$ categories (Additional file 1: Table S3), either in crude analyses or after adjusting for potential confounders. Considering the most adjusted model, in the 21 APOE $\varepsilon 4$ noncarriers HRs were also increased for total Se, Se-GPX, and Se-HSA, while in the 18 APOE $\varepsilon 4$ carriers an increased AD risk was apparent for total Se, Se-Met, and Se-Cys. Because of the small numbers within strata, however, these effect estimates were imprecise, as indicated by their wide confidence intervals.

\section{Discussion}

We investigated whether the risk of conversion to AD in patients with MCI is influenced by exposure to Se. We found that one out of several Se species in CSF was positively associated with subsequent $\mathrm{AD}$, and results were similar when we included in the outcome the few additional incident cases of neurodegenerative dementia; that is, the four cases of FTD and the two cases of LBD. The Se species associated with $\mathrm{AD}$ was the inorganic hexavalent one, selenate ( $\mathrm{Se}(\mathrm{VI})$ ), a species that lacks a direct physiological role by itself as it is not incorporated into selenoproteins. In addition, we found some associations between the organic form Se-Met and AD risk, but these were not confirmed in analyses based on the exclusion of cases diagnosed early during the follow-up.

$\mathrm{Se}(\mathrm{VI})$ is characterized by a peculiar metabolic pattern and toxicity $[8,11,14,24,46-50]$. Our findings, which 
Table 3 Linear regression analysis of CSF selenium species levels versus log-transformed values of biomarkers of Alzheimer's disease pathology ( $\beta$-amyloid and $p$-tau as dependent variables) in the 56 $\mathrm{MCl}$ study participants at baseline

\begin{tabular}{|c|c|c|c|c|c|}
\hline \multirow[t]{2}{*}{ Se species } & \multirow[t]{2}{*}{$(N)$} & \multicolumn{2}{|c|}{ Crude } & \multicolumn{2}{|c|}{ Adjusted } \\
\hline & & $\beta$ & $95 \% \mathrm{Cl}$ & $\beta$ & $95 \% \mathrm{Cl}$ \\
\hline \multicolumn{6}{|l|}{$\beta$-amyloid } \\
\hline Total Se & $(56)$ & 0.03 & $(-0.09$ to 0.15$)$ & 0.02 & $(-0.11$ to 0.15$)$ \\
\hline Inorganic Se & $(56)$ & -0.27 & $(-0.66$ to 0.11$)$ & -0.26 & $(-0.66$ to 0.15$)$ \\
\hline $\mathrm{Se}(\mathrm{IV})$ & (53) & -0.12 & $(-0.75$ to 0.51$)$ & -0.09 & ( -0.78 to 0.60$)$ \\
\hline $\mathrm{Se}(\mathrm{VI})$ & $(50)$ & -0.74 & $(-1.63$ to 0.16$)$ & -0.81 & $(-1.74$ to 0.13$)$ \\
\hline Organic Se & (56) & 0.16 & (0.02 to 0.30 ) & 0.18 & (0.01 to 0.34 ) \\
\hline Se-SelenoP & $(56)$ & 0.15 & $(-0.00$ to 0.31$)$ & 0.17 & $(-0.02$ to 0.36$)$ \\
\hline Se-Met & (54) & 1.87 & (0.52 to 3.23$)$ & 2.30 & (0.81 to 3.79 ) \\
\hline Se-Cys & $(12)$ & 1.01 & $(-3.17$ to 5.18$)$ & 2.93 & $(-1.33$ to 7.18$)$ \\
\hline Se-GPX & $(24)$ & 0.41 & $(-1.50$ to 2.33$)$ & 0.52 & $(-1.6$ \\
\hline Se-HSA & $(25)$ & -0.00 & $(-0.22$ to 0.21$)$ & 0.02 & $(-0.22$ to 0.25$)$ \\
\hline 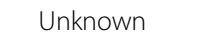 & $(56)$ & -0.08 & $(-0.57$ to 0.41$)$ & -0.14 & ( -0.72 to 0.43$)$ \\
\hline \multicolumn{6}{|l|}{$p$-tau } \\
\hline Total Se & $(56)$ & 0.06 & $(-0.08$ & 0.09 & $(-0.05$ to 0.23$)$ \\
\hline Inorganic Se & $(56)$ & -0.02 & $(-0.45$ to 0.41$)$ & -0.09 & $(-0.53$ to 0.35$)$ \\
\hline $\mathrm{Se}(\mathrm{IV})$ & (53) & -0.31 & $(-0.98$ to 0.37$)$ & -0.58 & $(-1.29$ to 0.14$)$ \\
\hline $\mathrm{Se}(\mathrm{VI})$ & (50) & 0.33 & $(-0.62$ to 1.28$)$ & 0.23 & $(-0.74$ to 1.20$)$ \\
\hline Organic Se & $(56)$ & 0.02 & $(-0.14$ to 0.18$)$ & 0.10 & $(-0.08$ to 0.28$)$ \\
\hline Se-SelenoP & $(56)$ & 0.03 & $(-0.15$ to 0.20$)$ & 0.13 & ( -0.08 to 0.33$)$ \\
\hline Se-Met & (54) & -0.26 & $(-1.83$ to 1.31$)$ & 0.10 & (-1.63 to 1.82$)$ \\
\hline Se-Cys & $(12)$ & -0.69 & $(-5.45$ to 4.60$)$ & -1.59 & ( -8.23 to 5.05$)$ \\
\hline Se-GPX & $(24)$ & -0.09 & $(-2.52$ to 2.34$)$ & -0.45 & ( -3.11 to 2.21$)$ \\
\hline Se-HSA & $(25)$ & 0.05 & $(-0.20$ to 0.30$)$ & 0.04 & $(-0.22$ to 0.31$)$ \\
\hline Unknown & $(56)$ & 0.61 & (0.10 to 1.12 ) & 0.75 & (0.17 to 1.33$)$ \\
\hline
\end{tabular}

Adjusted estimates are from a multivariable model including sex, age, education, and duration of sample storage as potential confounders. Values below the limit of detection were excluded from the analysis

$\beta$-amyloid $\mathrm{A} \beta_{1-42}, \mathrm{Cl}$ confidence interval, CSF cerebrospinal fluid, $\mathrm{MCl}$ mild cognitive impairment, $p$-tau phosphorylated tau protein, Se selenium, $\mathrm{Se}(\mathrm{IV})$ selenite, $\mathrm{Se}(\mathrm{VI})$ selenate, $\mathrm{Se}$-SelenoP selenoprotein P-bound $\mathrm{Se}$, Se-Met selenomethionine-bound $\mathrm{Se}, \mathrm{Se}-\mathrm{Cys}$ selenocysteine-bound $\mathrm{Se}, \mathrm{Se}-\mathrm{GPX}$ glutathione-peroxidase-bound $\mathrm{Se}, \mathrm{Se}-\mathrm{HSA}$ human serum albumin selenium-bound Se

were confirmed in analyses that take into account potential confounders such as education [51] and duration of sample storage [10], indicate that higher amounts of this Se species may predict and possibly cause AD. This association remained, but was weaker, after including in the multivariable model two biomarkers of Alzheimer's disease pathology, $\beta$-amyloid and $p$-tau levels. This finding indicates that these two CSF proteomic indicators may be mediators of $\mathrm{Se}(\mathrm{VI})$ toxicity, in which case they should be omitted from the regression model. Some association remained when these factors were included in the model, which could indicate that these two factors
Table 4 Crude and adjusted HR of developing Alzheimer's dementia in a Cox proportional hazards model, comparing participants with baseline selenium CSF concentrations above versus below (reference) the median value

\begin{tabular}{|c|c|c|c|c|c|c|}
\hline \multirow[t]{2}{*}{ Se species } & \multicolumn{2}{|c|}{ Crude } & \multicolumn{2}{|c|}{ Adjusted $^{a}$} & \multicolumn{2}{|c|}{ Adjusted $^{b}$} \\
\hline & $\mathrm{HR}$ & $95 \% \mathrm{Cl}$ & $\mathrm{HR}$ & $95 \% \mathrm{Cl}$ & $\mathrm{HR}$ & $95 \% \mathrm{Cl}$ \\
\hline Total Se & 1.6 & $(0.7-3.9)$ & 1.5 & $(0.6-3.8)$ & 2.0 & $(0.7-5.9)$ \\
\hline Inorganic Se & 0.8 & $(0.3-1.9)$ & 1.2 & $(0.5-3.0)$ & 1.0 & $(0.4-2.9)$ \\
\hline $\mathrm{Se}(\mathrm{IV})$ & 0.6 & $(0.2-1.4)$ & 0.7 & $(0.3-1.7)$ & 0.8 & $(0.3-2.2)$ \\
\hline $\mathrm{Se}(\mathrm{VI})$ & 2.6 & $(1.0-6.7)$ & 3.1 & $(1.0-9.5)$ & 2.4 & $(0.7-7.8)$ \\
\hline Organic Se & 1.4 & $(0.6-3.3)$ & 0.9 & $(0.3-2.4)$ & 1.0 & $(0.3-2.8)$ \\
\hline Se-SelenoP & 1.3 & $(0.6-3.2)$ & 0.9 & $(0.3-2.3)$ & 1.0 & $(0.3-2.8)$ \\
\hline Se-Met & 1.3 & $(0.5-3.0)$ & 1.2 & $(0.5-3.0)$ & 2.3 & $(0.9-5.9)$ \\
\hline Se-Cys & 0.6 & $(0.2-1.9)$ & 0.6 & $(0.2-1.9)$ & 0.6 & $(0.2-2.2)$ \\
\hline Se-GPX & 1.1 & $(0.5-2.6)$ & 1.0 & $(0.4-2.5)$ & 0.8 & $(0.3-2.2)$ \\
\hline Se-HSA & 1.2 & $(0.5-2.9)$ & 1.3 & $(0.5-3.5)$ & 1.7 & $(0.5-5.3)$ \\
\hline Unknown & 1.0 & $(0.4-2.4)$ & 2.7 & $(0.8-9.3)$ & 4.1 & $(0.9-18.8)$ \\
\hline
\end{tabular}

$\mathrm{Cl}$ confidence interval, CSF cerebrospinal fluid, $H R$ hazard ratio, $M C I$ mild cognitive impairment, Se selenium, Se(IV) selenite, Se(VI) selenate, Se-SelenoP selenoprotein P-bound Se, Se-Met selenomethionine-bound Se, Se-Cys

selenocysteine-bound Se, Se-GPX glutathione-peroxidase-bound Se, Se-HSA human serum albumin selenium-bound Se

${ }^{a}$ Adjusted for sex, age at entry, years of storage, and years of education

${ }^{b}$ Adjusted for sex, age at entry, years of storage, years of education, and

$\beta$-amyloid and phosphorylated tau protein level

may not mediate the entire possible neurodegenerative effect of $\mathrm{Se}(\mathrm{VI})$, or result from discrepancy in the CSF measures as indicators of neuropathology in the parenchyma. We also noted in the linear regression analysis an inverse association between baseline CSF Se(VI) (and more generally inorganic Se) and $\beta$-amyloid. This observation strengthens our findings from the Cox regression model, since low CSF $\beta$-amyloid levels are a marker of $\mathrm{AD}$ conversion risk in individuals with $\mathrm{MCI}$ [33]. The reason for such an inverse relation specifically restricted to inorganic Se and particularly to $\mathrm{Se}(\mathrm{VI})$ is difficult to surmise. It may be linked to some specific toxic properties such as pro-oxidant activity and promotion of protein misfolding by this Se species, as suggested or documented in laboratory and animal studies [16, 52-54] and suspected to occur in humans $[8,24]$. It also may relate to specific genetic features in $\mathrm{Se}(\mathrm{VI})$ metabolism characterizing some individuals [49].

A deleterious effect of $\mathrm{Se}(\mathrm{VI})$ on the central nervous system (CNS), and more generally inorganic Se, is biologically plausible, since these Se compounds have been long known to be very toxic $[24,55]$. Such an effect would contrast with suggestions of potential beneficial effects of Se and selenoproteins in AD progression from laboratory studies [56-58], although this hypothesis was recently contradicted by results from the PREADVISE study (Prevention of Alzheimer's Disease by Vitamin E and Selenium Trial) [32]. In that trial, 7540 asymptomatic 
older adults in North America were randomized to either placebo or $200 \mu \mathrm{g} /$ day Se as L-selenomethionine or both $\mathrm{L}$-selenomethionine and vitamin $\mathrm{E}$ for an average of 5.4 years, but there was no effect of any Se supplementation on dementia or $\mathrm{AD}$ incidence during the active supplementation period, or within a subset of the study cohort up to 6 additional years [32]. In the laboratory and veterinary medicine studies, inorganic and some organic Se species were shown to disrupt physiological pathways related to the etiology of neurological disorders or induce frank neurotoxicity [24]. This is particularly true for inorganic Se [59-61] including Se(VI) [62, 63], which may induce oxidative stress $[62,64,65]$ and cause genotoxicity and apoptosis [53, 66-69], particularly in neural cells [60]. This Se species may also be incorporated into protein as a replacement for sulfur, with consequent misfolding and functional impairment $[65,70]$ and endoplasmic reticulum stress $[54,71]$, all mechanisms potentially involved in AD etiology [72, 73]. In humans, specific neurotoxicity data are available for Se(VI) only for acute high-dose intoxication, which includes confusion, memory loss, anxiety, depression, irritability, insomnia, and dizziness [74, 75]. Exposure to inorganic Se species and $\mathrm{Se}(\mathrm{VI})$ in the human is limited, since $\mathrm{Se}(\mathrm{VI})$ levels in food are low compared with organic Se forms, and Se in drinking water (generally containing $\mathrm{Se}$ as $\mathrm{Se}(\mathrm{VI})$ ) contributes little to total Se intake [76]. However, there are scarce data on Se speciation in food, and some sources such as seafood or Se-enriched vegetables may contain higher levels of the inorganic $\mathrm{Se}(\mathrm{VI})$ species $[18,77]$. Dietary supplements may also represent a source of $\mathrm{Se}(\mathrm{VI})$, although they contain a mixture of Se species, in most cases represented mainly by its organic forms, especially Se-Met $[78,79]$.

The two key features of our study are the longitudinal design and the speciation approach. The cohort design allowed us to avoid reverse causality, the major potential limitation of certain case-control studies and all crosssectional studies. In fact, a progressive deterioration of nutritional status may characterize progression to $\mathrm{AD}$, in parallel with the worsening of cognitive impairment $[29,80]$, and selectively involve at an early stage of the disease some dietary factors including Se [81]. In addition, an effect of disease itself on Se tissue distribution and metabolism might exist. This effect is also suggested by the higher levels in post-mortem AD brains of the antioxidant SelenoP, which has been interpreted as a compensatory response to the oxidative stress characterizing disease progression [82]. Despite the strength of the longitudinal design of our study, we also took into account the possibility that some clinically undetected incipient disease already characterized our participants later converting to $\mathrm{AD}$, and therefore that some possibility of reverse causation still existed. We addressed this point by removing participants developing $\mathrm{AD}$ in the first period of follow-up, and our associations did not change or were even strengthened.

Focusing on Se speciation is something that has not been done before in similar research. Earlier studies assessed only overall Se levels or, very rarely, selenoprotein activity $[82,83]$. Since the chemical form of Se plays a major role in driving both its toxicological and nutritional effects, any exposure assessment based on overall Se content may be misleading $[8,9,11,15]$. Also neurotoxic properties of various Se species may differ considerably, independently of the overall Se exposure [24, 84]. These considerations accentuate the potential for bias due to exposure misclassification based on overall $\mathrm{Se}$ determination in epidemiologic studies [10, 21, 22], and highlight the relevance of speciation analysis in neurodegeneration research [30].

Another important feature of this study is the investigation of Se status in a CNS compartment. In fact, peripheral biomarkers of exposure, either based on overall Se or on single Se species, may not adequately predict CNS levels, especially in view of the known peculiarities of metabolism and retention of this element in the brain $[85,86]$ and the lack of correlation between some circulating $\mathrm{Se}$ species, especially its inorganic forms, with CSF levels [15, 43, 87]. Most case-control studies of AD have focused on peripheral indicators of exposure, such as blood, urine, hair, and nail samples, finding conflicting results ranging from adverse to protective $[27,28]$, while little association was noted with Se CSF levels [88-90].

A recent study based on 286 autopsied samples found Se brain content to be positively associated with brain neuropathology [91]. Se content was directly and positively correlated with neurofibrillary tangle severity, and in the highest exposure category a higher but statistically unstable risk of global Alzheimer's disease pathology and of Lewy bodies also emerged [91]. However, the crosssectional study design and lack of speciation analyses made it impossible to assess whether the higher Se levels preceded brain neuropathology or were due to compensatory selenoprotein synthesis $[7,8,92]$.

We also found an excess but statistically imprecise $A D$ risk associated with Se-HSA. However, the interpretation of this finding is challenging because of uncertainties about the exact nature of this chemical species, which might include both organic and inorganic Se forms $[10,15]$. Finally, we found some evidence of an excess AD risk associated with 'unknown' Se species, but the very wide confidence interval of the effect estimate and the uncertainties of the nature of this Se compound(s) hamper a reliable assessment of this finding.

We found some evidence of effect modification by the $\mathrm{APOE} \varepsilon 4$ status on $\mathrm{AD}$ risk, indicating that carriers of the APOE $\varepsilon 4$ allele may undergo an excess disease risk 
for higher levels of Se-Met and Se-SelenoP. Interestingly, an indication that APOE $\varepsilon 4$ status and Se metabolism may interact has been provided in an older Chinese population [93]. Se-Met is a Se form which has cytotoxic and pro-oxidant activities [69, 94], and this species has been recently observed to induce cognitive impairment in an animal model [95].

As already indicated, our study was small, with insufficient data to assess the associations within subgroups according to sex, age, or other factors. Similarly, we lacked data to assess the role of the three Se species (Se-Cys, Se-GPX, and Se-TXNRD) for which most samples (all for Se-TXNRD) fell below the LOD. Therefore, the involvement of these species in AD etiology could not be adequately or even partially assessed in the present study. Another limitation is the prospect of unmeasured confounding [96], which appears to be of particular relevance in epidemiologic studies dealing with Se [97]. Finally, the association between selenium as $\mathrm{Se}(\mathrm{VI})$ and $\mathrm{AD}$ risk found in our study may apply only to a population having the Se exposure typical of residents in the study area, already shown in previous studies to be comparable with the Italian national average [98-100], while such association may not necessarily exist in other populations characterized by considerably lower intake of this element $[90,101]$.

\section{Conclusions}

We found in persons with mild cognitive impairment of nonvascular origin that a higher cerebrospinal fluid content of an inorganic Se species, selenate, predicted progression toward $\mathrm{AD}$. No other Se form was related to either increased or increased AD risk. Since results were strengthened when participants who were diagnosed early during the follow-up were excluded from the analysis, thus limiting any effect of reverse causality, our results indicate that selenate levels in the central nervous system compartment may predict and possibly influence AD risk. However, the possibility of unmeasured confounding and the statistical imprecision of our results emphasize the need to replicate these findings in other studies.

\section{Additional file}

Additional file 1: Table S1. presenting APOE $\varepsilon 4$-adjusted linear regression analysis estimates of CSF Se species versus log-transformed values of biomarkers of Alzheimer's disease pathology ( $\beta$-amyloid and $\mathrm{p}$-tau as dependent variables) in the $\mathrm{MCl}$ study participants at baseline (values below the limit of detection for each specific species excluded from analysis). Most-adjusted estimates are from a multivariable model including sex, age, education, and duration of sample storage as potential confounders, in addition to APOE $\varepsilon 4$ allele carriership (presence/absence). Table S2. presenting crude and APOE $\varepsilon 4$-adjusted HRs of developing AD in a Cox proportional hazards model according to baseline CSF Se species in the $39 \mathrm{MCl}$ subjects at baseline having information about their APOE $\varepsilon 4$ status. Se exposure status defined as 0 (below or equal) and 1 (above) with reference to the median value. Table S3. presenting crude and adjusted HRs of developing AD in a Cox proportional hazards model, related to baseline CSF Se species in $\mathrm{MCl}$ subjects at baseline, according to APOE $\varepsilon 4$ carriership status (carriers, $N=$ 18; noncarriers, $N=21$ ). Se exposure status defined as 0 (below or equal) and 1 (above) with reference to the median value. (DOCX 29 kb)

\section{Abbreviations}

AD: Alzheimer's dementia; Cl: Confidence interval; CSF: Cerebrospinal fluid; FTD: Frontotemporal dementia; HR: Hazard ratio; IQR: Interquartile range; LBD: Lewy body dementia; LOD: Limit of detection; MCI: Mild cognitive impairment; Se(IV): Selenite; Se(VI): Selenate; Se-Cys: Selenocysteine-bound Se; Se-GPX: Glutathione-peroxidase-bound Se; Se-HSA: Human serum albumin selenium-bound Se; Se-Met: Selenomethionine-bound Se; Se-SelenoP: Selenoprotein P-bound Se; Se-TXNRD: Thioredoxin reductase-bound Se

\section{Acknowledgements}

The authors gratefully acknowledge all individuals who participated in this study.

\section{Funding}

Financial support to this study was provided by the Fondazione di Vignola and by the Local Health Unit of Reggio Emilia (to MV).

\section{Availability of data and materials}

To carry out the study we used confidential information for identification of participants according to the allowances and prescriptions issued by the local ethics committees which authorized this study, and in line with the Italian rules for data privacy in epidemiologic and biomedical research.

\section{Authors' contributions}

MV, AC, CM, MT, PFN, and BM designed the original study, and with KJR, TF, JW, and $\mathrm{GZ}$ analyzed and interpreted the data and drafted the article. ME and BM performed the laboratory analyses. AC, MT, GZ, and PFN recruited, assessed, and followed-up the study participants. All authors read and approved the final version of the manuscript.

\section{Ethics approval and consent to participate}

The study protocol was approved by the Modena University Hospital Ethics Committee (approval number 84/2015), in accordance with the principles of the Declaration of Helsinki of the World Medical Association. Written consent to use CSF for scientific research purposes was obtained from all the patients involved in the study before sampling.

\section{Consent for publication}

Not applicable.

\section{Competing interests}

The authors declare that they have no competing interests.

\section{Competing interests}

The authors declare that they have no competing interests.

\section{Publisher's Note}

Springer Nature remains neutral with regard to jurisdictional claims in published maps and institutional affiliations.

\section{Author details}

${ }^{1}$ CREAGEN-Environmental, Genetic, and Nutritional Epidemiology Research Center, Department of Biomedical, Metabolic, and Neural Sciences, University of Modena and Reggio Emilia, 287 Via Campi, Modena 41125, Italy. ${ }^{2}$ Center for Neurosciences and Neurotechnology, Department of Biomedical, Metabolic, and Neural Sciences, University of Modena and Reggio Emilia, 287 Via Campi, Modena 41125, Italy. ${ }^{3}$ Department of Epidemiology, Boston University School of Public Health, 715 Albany Street, Boston, MA 02118, USA. ${ }^{4}$ Department of Neurosciences, Azienda Ospedaliero-Universitaria di Modena, via del Pozzo 71, Modena, Italy. ${ }^{5}$ Helmholtz Zentrum München $\mathrm{GmbH}$ - German Research Center for Environmental Health $\mathrm{GmbH}$, Research Unit Analytical BioGeoChemistry, 1 Ingolstaedter Landstrasse, Neuherberg 
85764, Germany. ${ }^{6}$ Research Triangle Institute, Research Triangle Park, 3040 E Cornwallis Road, Durham, NC 27709, USA.

\section{Received: 29 August 2017 Accepted: 20 November 2017 Published online: 19 December 2017}

\section{References}

1. Hebert LE, Weuve J, Scherr PA, Evans DA. Alzheimer disease in the United States (2010-2050) estimated using the 2010 census. Neurology. 2013;80: 1778-83.

2. Prince M, Bryce R, Albanese E, Wimo A, Ribeiro W, Ferri CP. The global prevalence of dementia: a systematic review and metaanalysis. Alzheimers Dement. 2013:9:63-75. e62.

3. Power MC, Adar SD, Yanosky JD, Weuve J. Exposure to air pollution as a potential contributor to cognitive function, cognitive decline, brain imaging, and dementia: a systematic review of epidemiologic research Neurotoxicology. 2016;56:235-53.

4. Babadjouni RM, Hodis DM, Radwanski R, Durazo R, Patel A, Liu Q, et al. Clinical effects of air pollution on the central nervous system; a review. J Clin Neurosci. 2017:43:16-24.

5. Vinceti M, Wei ET, Malagoli C, Bergomi M, Vivoli G. Adverse health effects of selenium in humans. Rev Environ Health. 2001:16:233-51.

6. Hatfield DL, Tsuji PA, Carlson BA, Gladyshev VN. Selenium and selenocysteine: roles in cancer, health, and development. Trends Biochem Sci. 2014;39:112-20.

7. Labunskyy VM, Hatfield DL, Gladyshev VN. Selenoproteins: molecular pathways and physiological roles. Physiol Rev. 2014;94:739-77.

8. Jablonska E, Vinceti M. Selenium and human health: witnessing a Copernican revolution? J Environ Sci Health C Environ Carcinog Ecotoxicol Rev. 2015:33:328-68

9. Weekley $\mathrm{CM}$, Harris $\mathrm{HH}$. Which form is that? The importance of selenium speciation and metabolism in the prevention and treatment of disease. Chem Soc Rev. 2013:42:8870-94.

10. Vinceti M, Grill P, Malagoli C, Filippini T, Storani S, Malavolti M, et al. Selenium speciation in human serum and its implications for epidemiologic research: a cross-sectional study. J Trace Elem Med Biol. 2015;31:1-10.

11. Marschall TA, Bornhorst J, Kuehnelt D, Schwerdtle T. Differing cytotoxicity and bioavailability of selenite, methylselenocysteine, selenomethionine, selenosugar 1 and trimethylselenonium ion and their underlying metabolic transformations in human cells. Mol Nutr Food Res. 2016;60:2622-32.

12. Carlson BA, Lee JB, Tsuji P, Tobe R, Park JM, Schweizer U, et al. Selenocysteine tRNA [Ser]Sec: from nonsense suppressor tRNA to the quintessential constituent in selenoprotein biosynthesis. In: Hatfield D, Schweizer U, Gladyshev VN, editors. Selenium: Its Molecular Biology and Role in Human Health. 4th ed. New York: Springer Science + Business Media; 2016. p. 3-12.

13. Nogueira CW, Rocha JB. Toxicology and pharmacology of selenium: emphasis on synthetic organoselenium compounds. Arch Toxicol. 2011;85:1313-59.

14. Dolgova NV, Hackett MJ, MacDonald TC, Nehzati S, James AK, Krone PH, et al. Distribution of selenium in zebrafish larvae after exposure to organic and inorganic selenium forms. Metallomics. 2016;8:305-12.

15. Vinceti M, Solovyev N, Mandrioli J, Crespi CM, Bonvicini F, Arcolin E, et al. Cerebrospinal fluid of newly diagnosed amyotrophic lateral sclerosis patients exhibits abnormal levels of selenium species including elevated selenite. Neurotoxicology. 2013;38:25-32.

16. Burden CM, Elmore C, Hladun KR, Trumble JT, Smith BH. Acute exposure to selenium disrupts associative conditioning and long-term memory recall in honey bees (Apis mellifera). Ecotoxicol Environ Saf. 2016;127:71-9.

17. Mandrioli J, Michalke B, Solovyev N, Grill P, Violi F, Lunetta C, et al. Elevated levels of selenium species in cerebrospinal fluid of amyotrophic lateral sclerosis patients with disease-associated gene mutations. Neurodegener Dis. 2017;17:171-80

18. Fairweather-Tait SJ, Collings R, Hurst R. Selenium bioavailability: current knowledge and future research requirements. Am J Clin Nutr. 2010;91:1484S-91S

19. Fairweather-Tait SJ, Bao Y, Broadley MR, Collings R, Ford D, Hesketh JE, et al. Selenium in human health and disease. Antioxid Redox Signal. 2011;14:1337-83.

20. Vinceti M, Crespi CM, Malagoli C, Del Giovane C, Krogh V. Friend or foe? The current epidemiologic evidence on selenium and human cancer risk. J Environ Sci Health C Environ Carcinog Ecotoxicol Rev. 2013;31:305-41.

21. Vinceti M, Filippini T, Cilloni S, Crespi CM. The epidemiology of selenium and human cancer. Adv Cancer Res. 2017;136:1-48.
22. Vinceti M, Filippini T, Del Giovane C, Dennert G, Zwahlen M, Brinkman M, et al. Selenium for preventing cancer. Cochrane Database Syst Rev. (In press).

23. Seeher S, Carlson BA, Miniard AC, Wirth EK, Mahdi Y, Hatfield DL, et al. Impaired selenoprotein expression in brain triggers striatal neuronal loss leading to co-ordination defects in mice. Biochem J. 2014;462:67-75.

24. Vinceti M, Mandrioli J, Borella P, Michalke B, Tsatsakis A, Finkelstein Y. Selenium neurotoxicity in humans: bridging laboratory and epidemiologic studies. Toxicol Lett. 2014;230:295-303.

25. Ardissone A, Bragato C, Blasevich F, Maccagnano E, Salerno F, Gandioli C, et al. SEPN1-related myopathy in three patients: novel mutations and diagnostic clues. Eur J Pediatr. 2016;175:1113-8.

26. Killin LO, Starr JM, Shiue IJ, Russ TC. Environmental risk factors for dementia: a systematic review. BMC Geriatr. 2016:16:175.

27. Cicero CE, Mostile G, Vasta R, Rapisarda V, Signorelli SS, Ferrante M, et al. Metals and neurodegenerative diseases. A systematic review. Environ Res. 2017;159:82-94

28. Reddy VS, Bukke S, Dutt N, Rana P, Pandey AK. A systematic review and meta-analysis of the circulatory, erythrocellular and CSF selenium levels in Alzheimer's disease: A metal meta-analysis (AMMA study-I). J Trace Elem Med Biol. 2017;42:68-75

29. Vaz FNC, Fermino BL, Haskel MVL, Wouk J, de Freitas GBL, Fabbri R, et al. The relationship between copper, iron, and selenium levels and Alzheimer disease. Biol Trace Elem Res. doi:10.1007/s12011-017-1042-y.

30. Michalke B, Willkommena D, Drobyshevb E, Solovyev N. The importance of speciation analysis in neurodegeneration research. Trends Analyt Chem. doi:10.1016/j.trac.2017.08.008.

31. Oliveira CS, Piccoli BC, Aschner M, Rocha JBT. Chemical speciation of selenium and mercury as determinant of their neurotoxicity. Adv Neurobiol. 2017;18:53-83.

32. Kryscio RJ, Abner EL, Caban-Holt A, Lovell M, Goodman P, Darke AK, et al. Association of antioxidant supplement use and dementia in the prevention of Alzheimer's disease by Vitamin E and Selenium Trial (PREADViSE). JAMA Neurol. 2017:74:567-73.

33. Tondelli M, Bedin R, Chiari A, Molinari MA, Bonifacio G, Lelli N, et al. Role of cerebrospinal fluid biomarkers to predict conversion to dementia in patients with mild cognitive impairment: a clinical cohort study. Clin Chem Lab Med. 2015:53:453-60.

34. Winblad B, Palmer K, Kivipelto M, Jelic V, Fratiglioni L, Wahlund LO, et al. Mild cognitive impairment—-beyond controversies, towards a consensus: report of the International Working Group on Mild Cognitive Impairment. J Intern Med. 2004:256:240-6.

35. Albert MS, DeKosky ST, Dickson D, Dubois B, Feldman HH, Fox NC, et al. The diagnosis of mild cognitive impairment due to Alzheimer's disease: recommendations from the National Institute on Aging-Alzheimer's Association workgroups on diagnostic guidelines for Alzheimer's disease. Alzheimers Dement. 2011:7:270-9.

36. Fazekas F, Chawluk JB, Alavi A, Hurtig HI, Zimmerman RA. MR signal abnormalities at $1.5 \mathrm{~T}$ in Alzheimer's dementia and normal aging. AJR Am J Roentgenol. 1987;149:351-6.

37. Scheltens $P$, Leys $D$, Barkhof $F$, Huglo D, Weinstein HC, Vermersch $P$, et al. Atrophy of medial temporal lobes on MRI in "probable" Alzheimer's disease and normal ageing: diagnostic value and neuropsychological correlates. Neurol Neurosurg Psychiatry. 1992;55:967-72.

38. Dubois B, Feldman HH, Jacova C, Dekosky ST, Barberger-Gateau P, Cummings J, et al. Research criteria for the diagnosis of Alzheimer's disease: revising the NINCDS-ADRDA criteria. Lancet Neurol. 2007;6:734-46.

39. McKeith IG, Dickson DW, Lowe J, Emre M, O'Brien JT, Feldman H, et al. Diagnosis and management of dementia with Lewy bodies: third report of the DLB Consortium. Neurology. 2005;65:1863-72.

40. Gorno-Tempini ML, Hillis AE, Weintraub S, Kertesz A, Mendez M, Cappa SF et al. Classification of primary progressive aphasia and its variants. Neurology. 2011;76:1006-14.

41. Rascovsky K, Hodges JR, Knopman D, Mendez MF, Kramer JH, Neuhaus J, et al. Sensitivity of revised diagnostic criteria for the behavioural variant of frontotemporal dementia. Brain. 2011:134:2456-77.

42. Michalke $B$, Berthele $A$. Contribution to selenium speciation in cerebrospinal fluid samples. J Anal Atom Spectrom. 2011;26:165-70.

43. Solovyev N, Berthele A, Michalke B. Selenium speciation in paired serum and cerebrospinal fluid samples. Anal Bioanal Chem. 2013:405:1875-84.

44. US Environmental Protection Agency. Guidance for data quality assessment. Practical methods for data analysis. EPA QA/G9 QA00 update. Washington, DC: EPA; 2000 
45. Croghan CW, Egeghy PP. Methods of dealing with values below the limit of detection using SAS. Presented at Southeastern SAS User Group; St Petersburg, FL; September 22-24, 2003.

46. Gammelgaard B, Jackson Ml, Gabel-Jensen C. Surveying selenium speciation from soil to cell—forms and transformations. Anal Bioanal Chem. 2011;399:1743-63.

47. Lunoe K, Gabel-Jensen C, Sturup S, Andresen L, Skov S, Gammelgaard B. Investigation of the selenium metabolism in cancer cell lines. Metallomics. 2011;3:162-8

48. Gammelgaard B, Sturup S, Christensen MV. Human urinary excretion and metabolism of (82)Se-enriched selenite and selenate determined by LC-ICPMS. Metallomics. 2012:4:149-55.

49. Jager T, Drexler H, Goen T. Human metabolism and renal excretion of selenium compounds after oral ingestion of sodium selenate dependent on trimethylselenium ion (TMSe) status. Arch Toxicol. 2016;90:149-58.

50. Brigelius-Flohe R, Flohe L. Selenium and redox signaling. Arch Biochem Biophys. 2017;617:48-59.

51. Xu W, Tan L, Wang HF, Jiang T, Tan MS, Tan L, et al. Meta-analysis of modifiable risk factors for Alzheimer's disease. J Neurol Neurosurg Psychiatry. 2015;86:1299-306.

52. Weiller $M$, Latta $M$, Kresse $M$, Lucas $R$, Wendel $A$. Toxicity of nutritionally available selenium compounds in primary and transformed hepatocytes. Toxicology. 2004;201:21-30.

53. Choi AR, Jo MJ, Jung MJ, Kim HS, Yoon S. Selenate specifically sensitizes drug-resistant cancer cells by increasing apoptosis via G2 phase cell cycle arrest without P-GP inhibition. Eur J Pharmacol. 2015;764:63-9.

54. Van Hoewyk D. Defects in endoplasmic reticulum-associated degradation (ERAD) increase selenate sensitivity in Arabidopsis. Plant Signal Behav. doi:10.1080/15592324.2016.1171451.

55. Hogan GR, Pendleton RE. Comparative split dose effects of selenate and selenomethionine on erythropoiesis of mice. Bull Environ Contam Toxicol. 1996:56:622-9.

56. Jin N, Zhu H, Liang X, Huang W, Xie Q, Xiao P, et al. Sodium selenate activated Wnt/beta-catenin signaling and repressed amyloid-beta formation in a triple transgenic mouse model of Alzheimer's disease. Exp Neurol. 2017;297:36-49.

57. Rueli RH, Torres DJ, Dewing AS, Kiyohara AC, Barayuga SM, Bellinger MT, et al. Selenoprotein $S$ reduces endoplasmic reticulum stress-induced phosphorylation of tau: potential role in selenate mitigation of tau pathology. J Alzheimers Dis. 2017;55:749-62.

58. Zheng R, Zhang ZH, Chen C, Chen Y, Jia SZ, Liu Q, et al. Selenomethionine promoted hippocampal neurogenesis via the PI3K-Akt-GSK3beta-Wnt pathway in a mouse model of Alzheimer's disease. Biochem Biophys Res Commun. 2017:485:6-15

59. Ammar EM, Couri D. Acute toxicity of sodium selenite and selenomethionine in mice after ICV or IV administration. Neurotoxicology. 1981;2:383-6.

60. Maraldi T, Riccio M, Zambonin L, Vinceti M, De Pol A, Hakim G. Low levels of selenium compounds are selectively toxic for a human neuron cell line through ROS/RNS increase and apoptotic process activation. Neurotoxicology. 2011;32:180-7.

61. Boehler CJ, Raines AM, Sunde RA. Deletion of thioredoxin reductase and effects of selenite and selenate toxicity in Caenorhabditis elegans. PLoS One 2013;8:e71525

62. Benko I, Nagy G, Tanczos B, Ungvari E, Sztrik A, Eszenyi P, et al. Subacute toxicity of nano-selenium compared to other selenium species in mice. Environ Toxicol Chem. 2012;31:2812-20.

63. Nagy G, Benko I, Kiraly G, Voros O, Tanczos B, Sztrik A, et al. Cellular and nephrotoxicity of selenium species. J Trace Elem Med Biol. 2015;30:160-70.

64. Van Hoewyk D, Takahashi H, Inoue E, Hess A, Tamaoki M, Pilon-Smits EA. Transcriptome analyses give insights into selenium-stress responses and selenium tolerance mechanisms in Arabidopsis. Physiol Plant. 2008;132:236-53.

65. Grant K, Carey NM, Mendoza M, Schulze J, Pilon M, Pilon-Smits EA, et al. Adenosine 5'-phosphosulfate reductase (APR2) mutation in Arabidopsis implicates glutathione deficiency in selenate toxicity. Biochem J. 2011;438:325-35.

66. Biswas S, Talukder G, Sharma A. Selenium salts and chromosome damage. Mutat Res. 1997;390:201-5.

67. Cemeli E, Marcos R, Anderson D. Genotoxic and antigenotoxic properties of selenium compounds in the in vitro micronucleus assay with human whole blood lymphocytes and TK6 lymphoblastoid cells. Sci World J. 2006;6:1202-10.

68. Holmstrom A, Wu RT, Zeng H, Lei KY, Cheng WH. Nutritional and supranutritional levels of selenate differentially suppress prostate tumor growth in adult but not young nude mice. J Nutr Biochem. 2012;23:1086-91.

69. Bloch SR, Kim JJ, Pham PH, Hodson PV, Lee LEJ, Bols NC. Responses of an American eel brain endothelial-like cell line to selenium deprivation and to selenite, selenate, and selenomethionine additions in different exposure media. In Vitro Cell Dev Biol Anim. doi:10.1007/s11626-017-0196-4.

70. Dimkovikj A, Fisher B, Hutchison K, Van Hoewyk D. Stuck between a ROS and a hard place: analysis of the ubiquitin proteasome pathway in selenocysteine treated Brassica napus reveals different toxicities during selenium assimilation. J Plant Physiol. 2015;181:50-4.

71. Wang Y, Jiang L, Li Y, Luo X, He J. Excessive selenium supplementation induced oxidative stress and endoplasmic reticulum stress in chicken spleen. Biol Trace Elem Res. 2016;172:481-7.

72. Tonnies E, Trushina E. Oxidative stress, synaptic dysfunction, and Alzheimer's disease. J Alzheimers Dis. 2017:57:1105-21.

73. Van Raamsdonk JM, Vega IE, Brundin P. Oxidative stress in neurodegenerative disease: causation or association? Oncotarget. 2017:8:10777-8.

74. MacFarquhar JK, Broussard DL, Melstrom P, Hutchinson R, Wolkin A, Martin $C$, et al. Acute selenium toxicity associated with a dietary supplement. Arch Intern Med. 2010;170:256-61.

75. Morris JS, Crane SB. Selenium toxicity from a misformulated dietary supplement, adverse health effects, and the temporal response in the nail biologic monitor. Nutrients. 2013;5:1024-57.

76. Vinceti M, Crespi CM, Bonvicini F, Malagoli C, Ferrante M, Marmiroli S, et al. The need for a reassessment of the safe upper limit of selenium in drinking water. Sci Total Environ. 2013;443:633-42.

77. Castro Grijalba A, Fiorentini EF, Wuilloud RG. Ionic liquid-assisted separation and determination of selenium species in food and beverage samples by liquid chromatography coupled to hydride generation atomic fluorescence spectrometry. J Chromatogr A. 2017;1491:117-25.

78. Niedzielski P, Rudnicka M, Wachelka M, Kozak L, Rzany M, Wozniak M, et al. Selenium species in selenium fortified dietary supplements. Food Chem. 2016:190:454-9.

79. Kubachka KM, Hanley T, Mantha M, Wilson RA, Falconer TM, Kassa Z, et al. Evaluation of selenium in dietary supplements using elemental speciation. Food Chem. 2017:218:313-20.

80. Paglia G, Miedico O, Cristofano A, Vitale M, Angiolillo A, Chiaravalle AE, et al. Distinctive pattern of serum elements during the progression of Alzheimer's disease. Sci Rep. 2016;6:22769.

81. Olde Rikkert MG, Verhey FR, Sijben JW, Bouwman FH, Dautzenberg PL, Lansink $M$, et al. Differences in nutritional status between very mild Alzheimer's disease patients and healthy controls. J Alzheimers Dis. 2014;41:261-71.

82. Rueli RH, Parubrub AC, Dewing AS, Hashimoto AC, Bellinger MT, Weeber EJ, et al. Increased selenoprotein $P$ in choroid plexus and cerebrospinal fluid in Alzheimer's disease brain. J Alzheimers Dis. 2015;44:379-83.

83. Loef M, Schrauzer GN, Walach H. Selenium and Alzheimer's disease: a systematic review. J Alzheimers Dis. 2011;26:81-104.

84. Panter KE, Hartley WJ, James LF, Mayland HF, Stegelmeier BL, Kechele PO. Comparative toxicity of selenium from seleno-DL-methionine, sodium selenate, and Astragalus bisulcatus in pigs. Fund Appl Toxicol. 1996;32:217-23.

85. Kuhbacher M, Bartel J, Hoppe B, Alber D, Bukalis G, Brauer AU, et al. The brain selenoproteome: priorities in the hierarchy and different levels of selenium homeostasis in the brain of selenium-deficient rats. J Neurochem. 2009;110:133-42.

86. Benner MJ, Settles ML, Murdoch GK, Hardy RW, Robison BD. Sex-specific transcriptional responses of the zebrafish (Danio rerio) brain selenoproteome to acute sodium selenite supplementation. Physio Genomics. 2013;45:653-66.

87. Michalke B, Solovyev N, Vinceti M. Se-speciation investigations at neural barrier (NB). In: Se2017-200 Years of Selenium Research 1817-2017: 2017 Stockholm; 2017. http://se2017.se/wp-content/uploads/2017/06/Programand-Abstract-Book-Se2017-Final.compressed.pdf. Accessed 30 Nov 2017.

88. Meseguer I, Molina JA, Jimenez-Jimenez FJ, Aguilar MV, Mateos-Vega CJ, Gonzalez-Munoz MJ, et al. Cerebrospinal fluid levels of selenium in patients with Alzheimer's disease. J Neural Transm (Vienna). 1999;106:309-15.

89. Gerhardsson L, Blennow K, Lundh T, Londos E, Minthon L. Concentrations of metals, beta-amyloid and tau-markers in cerebrospinal fluid in patients with Alzheimer's disease. Dement Geriatr Cogn Disord. 2009;28:88-94.

90. Cardoso BR, Hare DJ, Bush Al, Li QX, Fowler CJ, Masters CL, et al. Selenium levels in serum, red blood cells, and cerebrospinal fluid of Alzheimer's disease patients: a report from the Australian Imaging, Biomarker \& Lifestyle flagship study of ageing (AIBL). J Alzheimers Dis. 2017:57:183-93.

91. Morris MC, Brockman J, Schneider JA, Wang Y, Bennett DA, Tangney CC, et al. Association of seafood consumption, brain mercury level, and APOE epsilon4 status with brain neuropathology in older adults. JAMA. 2016;315:489-97. 
92. Vinceti M, Maraldi T, Bergomi M, Malagoli C. Risk of chronic low-dose selenium overexposure in humans: insights from epidemiology and biochemistry. Rev Environ Health. 2009;24:231-48.

93. Gao S, Jin Y, Hall KS, Liang C, Unverzagt FW, Ma F, et al. Selenium level is associated with APOE epsilon4 in rural elderly Chinese. Public Health Nutr. 2009;12:2371-6.

94. Pettem CM, Weber LP, Janz DM. Cardiac and metabolic effects of dietary selenomethionine exposure in adult zebrafish. Toxicol Sci. 2017;159:449-60.

95. Naderi M, Salahinejad A, Jamwal A, Chivers DP, Niyogi S. Chronic dietary selenomethionine exposure induces oxidative stress, dopaminergic dysfunction, and cognitive impairment in adult zebrafish (Danio rerio). Environ Sci Technol. 2017;51:12879-88.

96. Rothman KJ, Greenland S, Lash TL. Modern Epidemiology. Philadelphia: Lippincott Williams \& Wilkins; 2012.

97. Vinceti M, Rothman KJ. More results but no clear conclusion on selenium and cancer. Am J Clin Nutr. 2016;104:245-6.

98. Morisi G, Patriarca M, Marano G, Giampaoli S, Taggi F. Age and sex specific reference serum selenium levels estimated for the Italian population. Ann Ist Super Sanita. 1989;25:393-403.

99. Vinceti M, Guidetti D, Bergomi M, Caselgrandi E, Vivoli R, Olmi M, et al. Lead, cadmium, and selenium in the blood of patients with sporadic amyotrophic lateral sclerosis. Ital J Neurol Sci. 1997;18:87-92.

100. Vinceti M, Crespi CM, Malagoli C, Bottecchi I, Ferrari A, Sieri S, et al. A casecontrol study of the risk of cutaneous melanoma associated with three selenium exposure indicators. Tumori. 2012;98:287-95.

101. Vinceti M, Filippini T, Cilloni S, Bargellini A, Vergoni AV, Tsatsakis A, et al. Health risk assessment of environmental selenium: emerging evidence and challenges. Mol Med Rep. 2017;15:3323-35.

\section{Submit your next manuscript to BioMed Central and we will help you at every step:}

- We accept pre-submission inquiries

- Our selector tool helps you to find the most relevant journal

- We provide round the clock customer support

- Convenient online submission

- Thorough peer review

- Inclusion in PubMed and all major indexing services

- Maximum visibility for your research

Submit your manuscript at www.biomedcentral.com/submit

) Biomed Central 